\title{
Performance Evaluation of Multi AgENT Agriculture SySTEM USING MARKOV PROCESSES
}

\author{
Hayam Seireg ${ }^{1}$, Ahmed Elmahalawy ${ }^{1}$, Yasser Omar², Adel S.El-Fishawy ${ }^{3}$ \\ and Fathi E. Abd El-Samie ${ }^{3}$ \\ ${ }^{1}$ Department of Computer Science \& Engineering, Faculty of Electronic \\ Engineering, Menoufia University, Menouf, Egypt \\ ${ }^{2}$ Arab Academy for Science Technology \& Maritime Transport, Cairo, Egypt \\ ${ }^{3}$ Faculty of Electronic Engineering, Menoufia University, Menouf, Egypt
}

\begin{abstract}
The multi agent agriculture system is a new application in AI to solve the problem of food shortage in the world and to decrease the gap between agriculture production and the need of people. In this paper we explorer the modeling and simulation of the new trend of the agriculture using AI with Markov processes. Simulation is used to check the performance of the proposed model. Steady state analysis of the proposed model is given. The steady state performance indicates that, the agriculture automation can close the gap between the actual production and the need of people. The main goal of using the multi-agents technology is to achieve high precision agriculture.
\end{abstract}

\section{KEYWORDS}

Markov processes, Steady state, Multi-agent system, Transition probability matrix, Complex real world systems.

\section{INTRODUCTION}

Hungry theory was developed by Thomas Robert Malthus. When he published this theory in 1798, he stated that the population increased in geometric series. The geometric series is a sequence of numbers where each successive term can be obtained by multiplying the previous term by a fixed number and Thomas Robert Malthus theorized that the food production $[1,2,3]$ grew in arithmetic series that is the sum of a sequence, in which each term is calculated, from the previous one by adding a constant. Thomas Robert mentioned that the growth of the population would eventually diminish the ability of the world to feed itself.

From 200 years ago, there were less than one billion living on the earth. Today, the UN calculations stated that there are over 7 billion of people. The growth of population was increasing slowly but it has been increased exponentially between 1900 and 2000. The growth of the population grew three times greater than during the entire previous history of humanity. From 100 years ago, the growth of the population has been jumped dramatically from 1.5 to 6.1 billion. It is important to focus on managing how to increase the food production more than the population growth. 


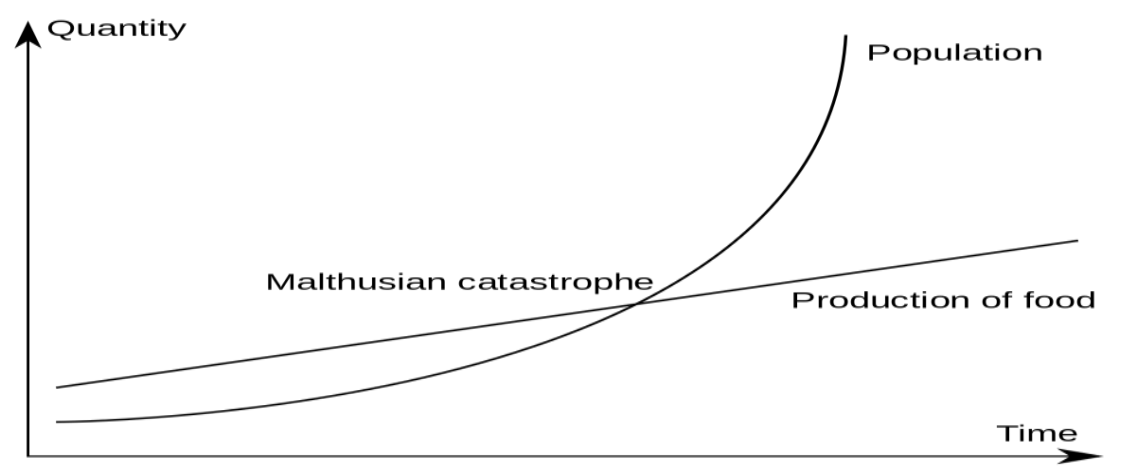

Figure 1. Increasing of gap between the need and production of food

\subsection{As the FAO states that there are five systems which aspects the food losses}

Agriculture production [4]: - During harvesting operation, the mechanical damage or spillage may cause losses and crops sorted out post-harvest, etc.

\subsubsection{Post-harvesting handling and storage}

The storage and transportation may cause losses due to spillage and degradation during handling between farm and distribution.

\subsubsection{The Processing}

The industrial or domestic processing may cause losses due to spillage and degradation.

\subsubsection{Distribution}

The market system may cause losses and waste of the resources during consumption.

\subsubsection{Consumption}

The household level may cause losses and waste of the resources during consumption.

\section{Productions}

The growing of the land is increasing in an arithmetic series, the gap has been increased between the growth of the population and the growth of productivity as shown in Figure 1. The components of our agriculture were started by eating from forest and the animal \& plant grows by nature. Then the people started to farm plant using seeds, land, sun, water .....Then they add of the fertilizing (organic or nonorganic). Then, changing the methodology of agriculture has changed to green agriculture ....... Then using the machines to increase the productivity and then Genetic, Engineers discovered hormones for plants, aquaponic farms [5] (due to shortage of fresh water, shortage of land, green houses. Improving the irrigation methodologies and improving of soil land have become a must. Aquaponic is a good solution to increase the productivity of the food $[6,7]$ that is the way to grow your own fish and vegetables at the same time, that there is no need for soil. The plants take it as a feed from the waste of the fish instead of throwing it in the ocean. The sustainable organic crop production and consumption water is the main goal for the future and it will be achieved by aquaponics [8]. We can consider the fact that aquaponics is a good way for feeding the billions of populations on the earth that anyone could do it in his small house to have his own food. It tends to produce a higher food yield in minimal space. As the fish 
are living in the water and the plants are feed from the nutrients from the water. Then, the plants are cleaning the water which can be cycled back to the fish. There is another way to increase the productivity of food by greenhouse [9] in a structure with walls and roof made of glass or traces of iron with covering by transparent plastic, such that each type of plants needs a special climatic condition which could be achieved so many green houses are associated with equipment including heater, cooling. Lighting and may be controlled by a computer to optimize condition for plant growth, Netherlands and then England in the $17^{\text {th }}$ century used the greenhouse concept. Today, the many largest greenhouses in the world are in Netherlands and they can produce millions of tons of vegetables every year. The greenhouse [10] has their unique environment that manage their requirements, the pests and diseases and extremes of heat and humidity must be controlled, another gap of productivity, for controlling of pests (warms, insects...more). In this paper, we improve the methodology of food production in the world using AI automation of farming to maximize the productivity.

\section{Modelling Of The Multi-Agent for Agriculture}

Markov process using multi-agent is a new method for modelling complex real-world systems agriculture. This paper focuses on multi-agent model for agriculture, This model will describe the three states that are represented by three actors, smart sensors, the machine and the farmer. The first actor is the smart sensors using Internet of things (IOT) $[11,12,13]$ that detect the diseases of the plant and also detect if the plants needs water and also detect whether the climate is suitable for the plant respect to the degree of the temperature. IoT can be used in agricultural sectors to sense the humidity, temperature, pressure in an area. There are different sensors used for different purposes, temperature sensors, humidity sensors, pressure sensors etc. The second actor is the machine that recognizes the problem for suitable decision making. The first step is that the machine takes the data from the smart sensors $[14,15]$ then the machine makes data interpretation or data analysis which is the process of organizing, manipulating, querying and summarizing. It is difficult to the farmer to recognize the large number of data, we can use tools to identify the data and get the relationships between the variables to be easy to the farmer to take decision depending on the machine results. Also noted it will be difficult to automate the decision for this case, the farmer must take decision personally. Sometimes wrong data from the smart sensors $[16,17,18,19]$ might give a false alarm. While the data analysis is doing the processes may identify these errors but sometimes the machine can not recognize these errors, which resulted in taking a wrong decision by the farmer. The third actor is the farmer who takes the decision depending on the data analysis that means recognizing the adjustment of the important parameter and taking the action that is needed for knowing the right decision for using it in practice. Sometimes, the farmer strategies may be wrong regarding missing knowledge and information related to the agriculture methods and the farmer is restricted by the rules of their countries and their policies he should do it. There is a risk regarding the change of the government policies. Many factors affect the decision of the farmer. As the farmer should have risk management skills to better anticipate problems. There is no formal definition of the multi-agent [20], but the most common features that were agreed on. Multiple agents should be acting in one environment that this requirement should be taken into consideration that the multiple agents should have the same type of the input and the actions that have been taken should be affected some part or all the common environment state of the multiple agents [21].

\section{Markov State Process}

The modelling and simulation is one of the tools to achieve this goal. We used Markov state diagram to measure the performance of the new AI multi agent system to achieve this goal. We 
used Markov state diagram as shown in Figure 2. We generated the Transition probability matrix as shown in equation (1)

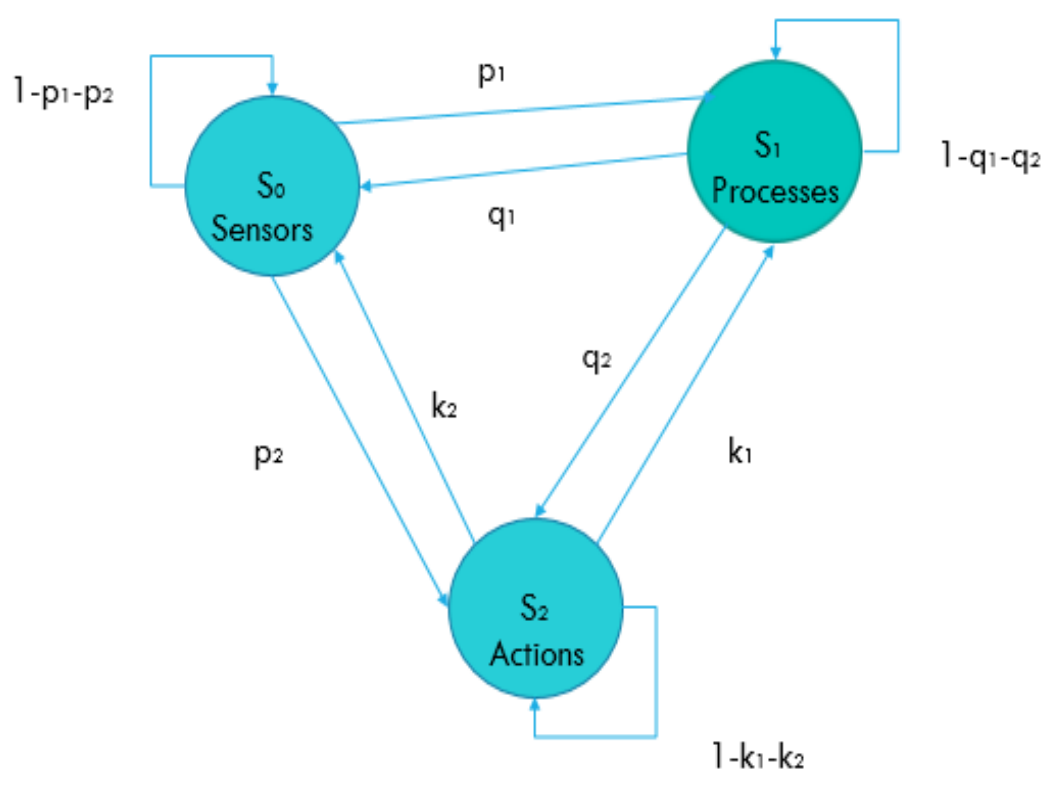

Figure 2. Markov state diagram

Table 1 Parameters in Markov state diagram.

\begin{tabular}{|l|l|}
\hline \multicolumn{1}{|c|}{ Parameter } & \multicolumn{1}{c|}{ Description } \\
\hline $\mathrm{S}_{0}$ & Represents the probability of sensing of the sensors. \\
\hline $\mathrm{S}_{1}$ & $\begin{array}{l}\text { Represents the probability of success of processing such as recognition, } \\
\text { filtration....etc. }\end{array}$ \\
\hline $\mathrm{S}_{2}$ & Represents the probability of action taken due to sensing. \\
\hline $\mathrm{p}_{1}$ & Probability of transition from sensor state $\mathrm{S}_{0}$ to the processes state $\mathrm{S}_{1}$. \\
\hline $\mathrm{q}_{1}$ & Probability of transition from processes state $\mathrm{S}_{1}$ to the sensor state $\mathrm{S}_{0}$. \\
\hline $\mathrm{q}_{2}$ & Probability of transition from processes state $\mathrm{S}_{1}$ to the sensor state $\mathrm{S}_{0}$. \\
\hline $\mathrm{k}_{1}$ & Probability of the transition from actions state $\mathrm{S}_{2}$ to the processes state $\mathrm{S}_{1}$. \\
\hline $\mathrm{k}_{2}$ & Probability of the transition from actions state $\mathrm{S}_{2}$ to the sensor state $\mathrm{S}_{0}$. \\
\hline $\mathrm{p}_{2}$ & Probability of the transition from sensor state $\mathrm{S}_{0}$ to the actions state $S_{2}$. \\
\hline $1-\mathrm{p}_{1}-\mathrm{p}_{2}$ & Probability of the transition from sensor state $\mathrm{S}_{0}$ return to the same state. \\
\hline $1-\mathrm{q}_{1}-\mathrm{q}_{2}$ & Probability of the transition from processes state $S_{1}$ return to the same state. \\
\hline $1-\mathrm{k}_{1}-\mathrm{k}_{2}$ & Probability of the transition from processes state $S_{2}$ return to the same state. \\
\hline
\end{tabular}

The transition from sensing state S0 to the processes state S1 has probability $\mathrm{p} 1$, if the sensors didn't detect change of temperature or disease affected the plants in state S0 after a period, the transition will have probability 1-p1-p2. In case, when the machine received the data from the sensor and has been interpreted by the machines which have the transition from processes state $\mathrm{S} 1$ to action state $\mathrm{S} 2$ should be placed, the transition will have probability $\mathrm{q} 2$. If there is no change in the data and it is the same process state $S 1$, the transition will have probability 1-q1q2. If there is no action, S2 state should be return to same state which will have probability of transition 1-k1-k2, if actions of state S2 already have been taken and the solution solved the problem by killing the insects with the pesticides or if the sensor detects that the plant is effected by high temperature which will take an decision to irrigate the crops, it has to return back to the sensors S0 state to detect if there is anything else affected the plants, the transition probability 
will be k2. If the transition from sensors state S0 to the actions S2 state the transition will have probability $\mathrm{p} 2$ and if the transition from actions state $\mathrm{S} 2$ to the processes $\mathrm{S} 1$ state, the transition will have probability $\mathrm{k} 1$. The transition from state $\mathrm{S} 1$ processes to the sensors state $\mathrm{S} 0$ the transition will have probability q1 as shown in Figure 2, which represents Markov state diagram of this model.Markov state diagram depends on the states and transitions [22,23,24,25]. The state diagram in Figure 2 is normal.

Transition probability matrix $\mathrm{P}=[\mathrm{TPM}]$

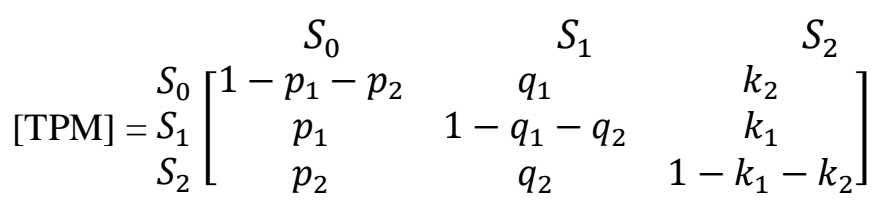

\subsection{Steady State Models}

\subsubsection{Local Balance Equations}

From Figure 2 we can deduce the local balance equations with the rule that the flow in is equal to flow out of each state at balance.

$\pi_{\mathrm{n}+1}=\mathrm{P} \cdot \pi_{\mathrm{n}}$

$$
\left[\begin{array}{l}
S_{0} \\
S_{1} \\
S_{2}
\end{array}\right]=\left[\begin{array}{ccc}
1-p_{1}-p_{2} & q_{1} & k_{2} \\
p_{1} & 1-q_{1}-q_{2} & k_{1} \\
p_{2} & q_{2} & 1-k_{1}-k_{2}
\end{array}\right]\left[\begin{array}{l}
S_{0} \\
S_{1} \\
S_{2}
\end{array}\right]
$$

$\mathrm{S}_{0}\left(\mathrm{p}_{1}+\mathrm{p}_{2}\right)=\mathrm{q}_{1} \mathrm{~S}_{1}+\mathrm{k}_{2} \mathrm{~S}_{2}$

$\mathrm{S}_{1}\left(\mathrm{q}_{1}+\mathrm{q}_{2}\right)=\mathrm{S}_{0} \mathrm{p}_{1}+\mathrm{S}_{2} \mathrm{k}_{1}$

$\mathrm{S}_{0}+\mathrm{S}_{1}+\mathrm{S}_{2}=1$

When $\mathrm{p}_{1}=\mathrm{k}_{1}=\mathrm{q}_{1}, \mathrm{p}_{2}=\mathrm{q}_{2}=\mathrm{k}_{2}$, we consider them equal opportunity probability of transitions and their range of values are between 0 and 1 .

From (6) $\mathrm{S}_{0}=1-\mathrm{S}_{1}-\mathrm{S}_{2}$

From (4), (7)

$\left(1-\mathrm{S}_{1}-\mathrm{S}_{2}\right)\left(\mathrm{p}_{1}+\mathrm{p}_{2}\right)=\mathrm{q}_{1} \mathrm{~S}_{1}+\mathrm{k}_{2} \mathrm{~S}_{2}$

$\left(\mathrm{p}_{1}+\mathrm{p}_{2}\right)=\left(\mathrm{q}_{1}+\mathrm{p}_{1}+\mathrm{p}_{2}\right) \mathrm{S}_{1}+\left(\mathrm{k}_{2}+\mathrm{p}_{1}+\mathrm{p}_{2}\right) \mathrm{S}_{2}$

From (5), (6)

$\mathrm{S}_{1}\left(\mathrm{q}_{1}+\mathrm{q}_{2}\right)=\left(1-\mathrm{S}_{1}-\mathrm{S}_{2}\right)\left(\mathrm{p}_{1}+\mathrm{S}_{2} \mathrm{k}_{1}\right)$

$\mathrm{S}_{1}\left(\mathrm{q}_{1}+\mathrm{q}_{2}+\mathrm{p}_{1}\right)=\mathrm{p}_{1}+\left(\mathrm{k}_{1}-\mathrm{p}_{1}\right) \mathrm{S}_{2}$

$\mathrm{S}_{1}=\left(\left(\mathrm{p}_{1}+\left(\mathrm{k}_{1}+\mathrm{p}_{1}\right) \mathrm{S}_{2}\right) /\left(\mathrm{q}_{1}+\mathrm{q}_{2}+\mathrm{p}_{1}\right)\right)$

From (9), (12)

$\left(\mathrm{p}_{1}+\mathrm{p}_{2}\right)=\left(\left(\left(\left(\mathrm{p}_{1}+\left(\mathrm{k}_{1}-\mathrm{p}_{1}\right)\right)\left(\mathrm{q}_{1}+\mathrm{p}_{1}+\mathrm{p}_{2}\right)\right) /\left(\mathrm{q}_{1}+\mathrm{q}_{2}+\mathrm{p}_{1}\right)\right)+\left(\mathrm{k}_{2}+\mathrm{p}_{1}+\mathrm{p}_{2}\right)\right) \mathrm{S}_{2}$

$\mathrm{S}_{2}=\left(\left(\left(\mathrm{p}_{1}+\mathrm{p}_{2}\right)\left(\mathrm{q}_{1}+\mathrm{q}_{2}+\mathrm{p}_{1}\right)\right) /\left(\mathrm{p}_{1}+\left(\mathrm{k}_{1}-\mathrm{p}_{1}\right)\left(\mathrm{q}_{1}+\mathrm{p}_{1}+\mathrm{p}_{2}\right)+\left(\mathrm{k}_{2}+\mathrm{p}_{1}+\mathrm{p}_{2}\right)\right)\right.$

Drawing $\mathrm{S}_{0} \mathrm{~S}_{2}$ under condition $\mathrm{p}_{1}=0, \mathrm{p}_{2}=1$ and $\mathrm{p}_{1}=1, \mathrm{p}_{2}=0$

If $\mathrm{p}_{1}=\mathrm{k}_{1}=\mathrm{q}_{1}, \mathrm{p}_{2}=\mathrm{q}_{2}=\mathrm{k}_{2}$

$\mathrm{S}_{2}=\left(\left(\mathrm{p}_{1}+\mathrm{p}_{2}\right)\left(2 \mathrm{p}_{1}+\mathrm{p}_{2}\right) /\left(3 \mathrm{p}_{1}+\mathrm{p}_{2}\right)\right)$ 
$\mathrm{p}_{2}$

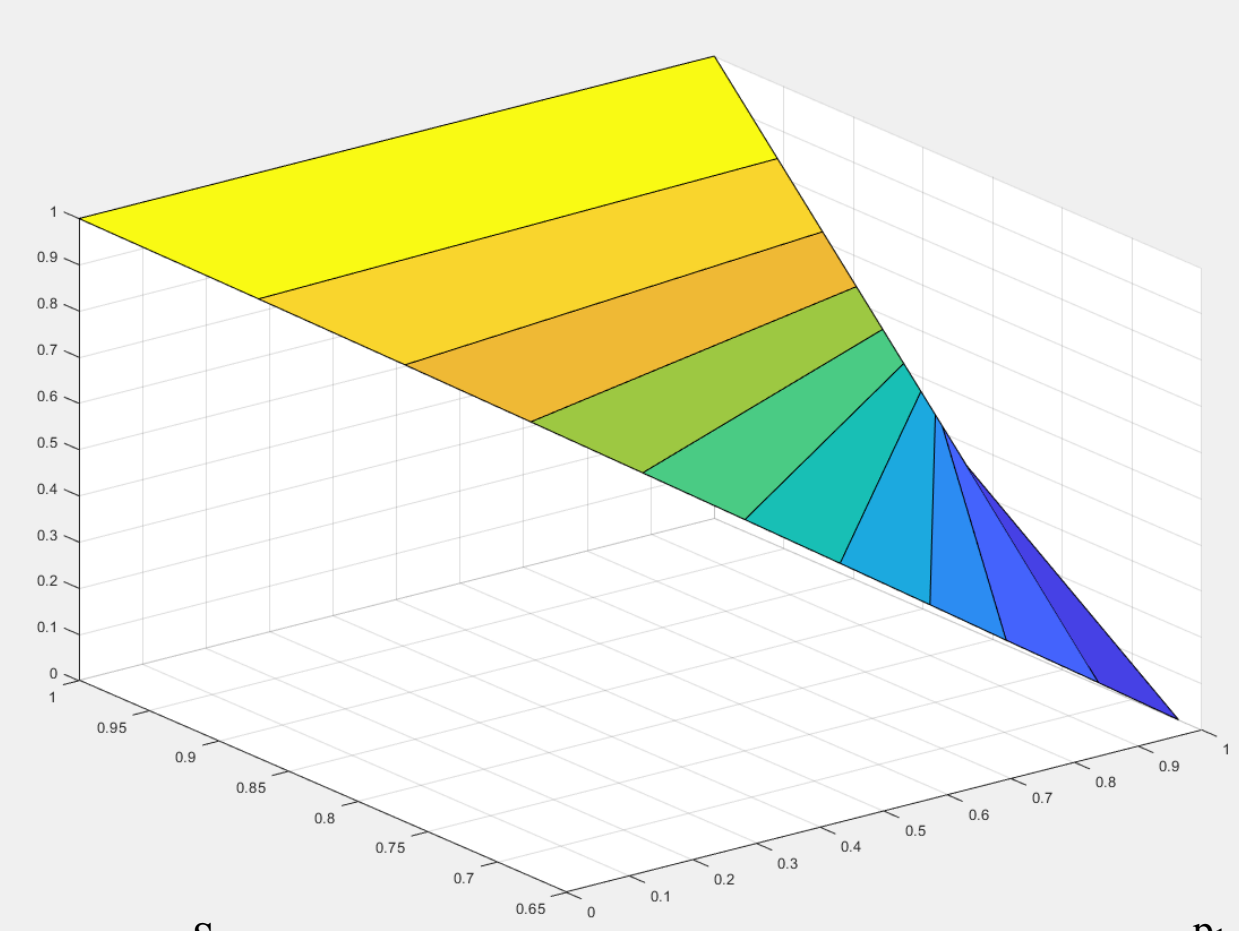

$\mathrm{S}_{2}$

$\mathrm{p}_{1}$

Figure 3. Represent the values of $S_{2}$

From Figure 3 for the probability of existing in action state is very small when $\mathrm{p}_{1}, \mathrm{p}_{2}$ are very small and the probability of existing in feedback state is decreased linearly as $\mathrm{p}_{1}, \mathrm{p}_{2}$ increased to the maximum of $S_{2}=0.7$ and minimum of $S_{2}=0.0$ then we have to optimize between the transition of $\mathrm{p} 1, \mathrm{p} 2$ to make the system to be very fast to take design as fast of taking action as fast of productivity of food. i.e. as fast of killing the pests will result of keeping the crops

If $\mathrm{p}_{1}=\mathrm{k}_{1}$

$\mathrm{q}_{1}=\left(\left(\mathrm{p}_{1}\right) /\left(2 \mathrm{p}_{1}+\mathrm{p}_{2}\right)\right)$

From (6), (15), (16)

$\mathrm{S}_{0}=1-\left(\left(\mathrm{p}_{1}\right) /\left(2 \mathrm{p}_{1}+\mathrm{p}_{2}\right)\right)-\left(\left(\left(\mathrm{p}_{1}+\mathrm{p}_{2}\right)\left(2 \mathrm{p}_{1}+\mathrm{p}_{2}\right)\right) /\left(3 \mathrm{p}_{1}+\mathrm{p}_{2}\right)\right)$

By plotting the equation (16) for S0 which represents the probability of existing in sensing mode, if all states have equal probability, then the system will reach the maximum productivity but if not it means that the system will be biased and the productivity will be less. 


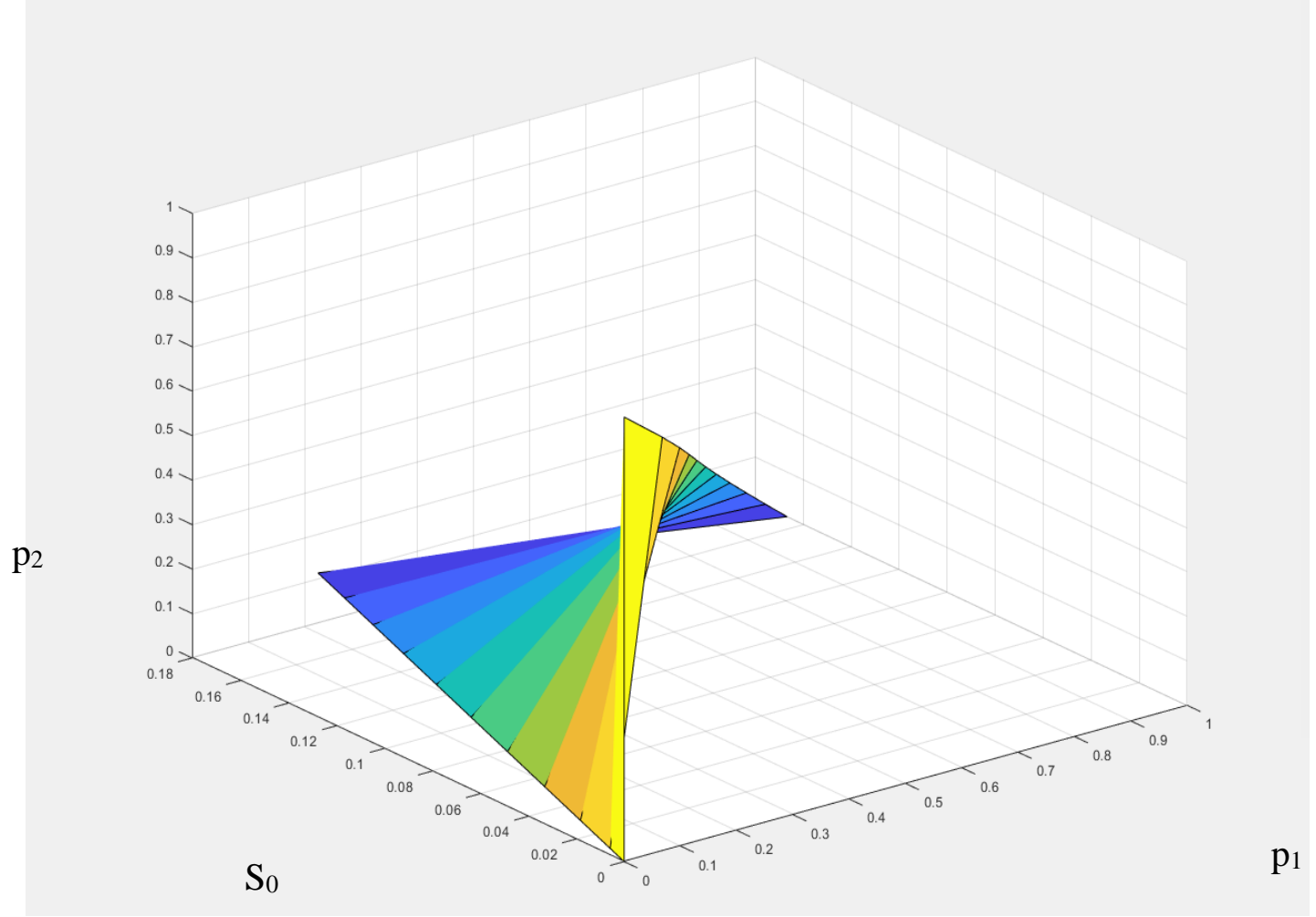

Figure 4. Represent the values of S0

Similarly, Figure 4 shows the probability in existing of sensing state growing linearly to 3.7 regardless of the values of $\mathrm{p} 1$ or $\mathrm{p} 2$, by means if the probability of existing in sensing is very high, the probity of production will decrease. I.e. if we take a long time for detecting of pests, the pests will destroy the production of crops, also, if we take long time to detect the need of irrigation, the crop may be destroyed, then we have to make it quickly to avoid the drawbacks

\section{Analysis of the Markov Process}

The probability of the time taken to decide [26] which method we should use to solve the problem. The use of the graph of each state help us to estimate the time that is taken in each state to focus on which states takes longer time that will cause failure of the system. The time is very important in taking any decision. If the decision was late, it can destroy everything, as example if the smart sensors detect that the insects are eating the crops and then the decision of using the pesticides was late, here the decision is not affected by the fact that all crops are already eaten by the insects. For that the process to identify which method should be used and taken an action will not be affected.

\section{COnClusions}

In this paper, we explored the hungry problem and lower productivity of the farmers. We proposed the multi agent AI to cover the gap between production of food and the requirements of people (protesters). We evaluated the performance of the new technology to recover the gap which indicates that we can recover the gap using AI, we modelled this problem by Markov state diagram in discrete model, deduced transition probability matrix of our model and we derived the local balance equations. The conclusion proves that using the 1st order Markov processes by 
solving the local balance equations helps in finding the points of recovery from the figures and equations.

\section{REFERENCES}

[1] Porter et al.,(2014)," Climate change and food security: risks and responses", Food and Agriculture Organization of the United Nations.

[2] Notaro M, Mauss A, Williams JW,(2012)," Projected vegetation changes for the American southwest: Combined dynamic modeling and bioclimatic envelope approach" Ecological Applications";22:1365-1388.

[3] Zenebe Mekonnen,(2018),"Observed and Projected Reciprocate Effects of Agriculture and Climate Change: Implications on Ecosystems and Human Livelihoods", DOI: 10.5772/intechopen.79118.

[4] FAO. (2016)b. SAVE FOOD: Global initiative on food loss and waste reduction [Website] (available at www.fao.org/save-food). Accessed November 2016.

[5] Rakocy JE (2012) Aquaponics-Integrating Fish and Plant Culture, Oxford, UK: Wiley-Blackwell. 344-386.

[6] Sommerville C, Cohen M, Pantanella E, Stankus A, Lovatelli A (2014) " Small-scale aquaponics food production-integrated fish and plant farming", FAO Fisheries and Aquaculture Technical Paper No. 589, FAO, Rome.

[7] Rakocy JE (2012) Aquaponics-integrating fish and plant culture. In:Tidwell JH (ed) Aquaculture production systems. Wiley-Blackwell, Oxford, p 344-386.

[8] Kloas W, Rennert B, Van Ballegooy C, Drews M (2008) “ Aquaponic system for vegetable and fish production". US Patent and Trademark Office Publication no. US20110131880 A1. Available at www.google. com/ patents/US20110131880 (accessed on 10 March 2015).

[9] Sushama Arjun Kolhe, S. A Annadate,(2012) “Implementation of Green House Automation using ARM7 Controller", International Journal of Computer Applications (0975 - 888), Volume 47No.20.

[10] S.H. Sadati, AM.Sahari,(2008) "Design and Simulation of an automated system for greenhouse using Lab VIEW", American-Eurasian J.Agric and Environ Sci, 3(2):279-284,ISSN 1818-6769.

[11] Masinde, M. and Bagula, A., (2013) " Sense Weather: Sensor-Based Weather Monitoring System for Kenya”, In: The 1ST-Africa 2013 Conference Proceedings, Nairobi, Kenya, 29-31 May 2013, IEEE Xplore, pp. 1-13

[12] Charith Perera, Arkady Zaslavsky, Peter Christen. Dimitrios Georgakopoulos(2013) "Context Aware Computing for The Internet of Things: A Survey". IEEE Commun Surveys Tutorials 16(1), DOI: https://doi.org//10.1109/SURV.2013.042313.00197.

[13] Orhan. Dagdeviren, Ilker. Korkmaz, Fatih. Tekbacak, Kayhan. Erciyes (2011),” A Survey of Agent Technologies for Wireless Sensor Networks",IETE Technical Rev, 28 (2).

[14] K. Dang, H. Sun, C. Jean-Pierre, J. Garcia-Vidal, J.M. Barcelo-Ordinas, H.L. Shi, K.M. Hou.,(2018), “ Wireless Multimedia Sensor Network for plant disease detections". @ https://hal.archives-ouvertes.fr/docs/.

[15] D.D. Chaudhary, S.P. Nayse, L.M. Waghmare,(2011),"Application of Wireless Sensor Networks for Greenhouse Parameter Control in Precision",Agriculture, Int $\mathrm{J}$ Wireless Mobile Networks, 3 (N0) (February 2011), p. 1 
[16] N. Sakthipriya.(2014) “An Effective Method for Crop Monitoring Using Wireless Sensor Network”. Middle-East J Scientific Res 20;9.

[17] Jyoti tewari, Swati Arya, Prem Narayan Singh (2013). “Approach of Intelligent Software Agents in Future Development”, IJARCSSE, ISSN:2277128X, May 2013.

[18] Shipra. Thessler, Lammer. Kooistra, Frederick. Teye, Hanna. Huitu, Anold K. Bregt(2011), “ Geosensors to Support Crop Production": Current Applications and User Requirements Sensors, 11 pp. 6656-6684, 10.3390/s110706656.

[19] Sherine M. Abd El-Kader, Basma M. Mohammad El-Basioni,(2013) "Precision farming solution in Egypt using the wireless sensor network technology”,Egyptian Informatics J, 14 ,pp. 221-233

[20] Li H., Karray F., Basir O., Song I,(2006) "Multi-Agent Based Control of a Heterogeneous System". Journal of Advanced Computational Intelligence and Intelligent Informatics, vol 10, No. 2, pp 161-167.

[21] Schreinemachers, P., \& Berger, T. (2006) "Land use decisions in developing countries and their representation in multi-agent systems". Journal of Land Use Science, 1(1), 29-44.

[22] Chang-Xing, L., (2009) "Probe into the teaching of probability theory and stochastic processes", Proceedings of the International Conference on Computational Intelligence and Software Engineering, Dec. 11-13, IEEE Xplore Press, Wuhan, pp: 1-4. DOI: 10.1109/CISE.5366432.

[23] Cinlar, E., (2013)," Introduction to Stochastic Processes", 1st Edn.,Elsevier, ISBN-10: 0486497976, pp: 416.

[24] Grimmett, G. and D. Stirzaker, (2001) Probability and Random Processes, 3rd Edn., Oxford University Press, New York, ISBN-10: 0198572220, pp: 596.

[25] Lawler, G.F., (2006) Introduction to Stochastic Processes, 2nd Edn., Chapman and Hall/CRC, ISBN-10: 158488651X, pp: 234.

[26] Hsu, H.P., (2010) Schaum's Outline of Probability, Random Variables, and Random Processes, 2nd Edn., McGraw-Hill, New York, ISBN-10: 0071632891, pp: 432. 


\section{Authors}

Hayam Reda Seireg was teaching assistant at El-Shorouk Academy, she had her master degree from Arab Academy For Science, Technology \& Maritime Transport and she is working on her PhD. Her interest is in artificial Intelligence mainly Agent technology and multi Agent System and machine learning.

Dr. Ahmed M. Elmahalawy is currently Assistant Professor at Menoufia University Faculty of Electronics Engineering, in the Department of Computer Science and Engineering. His interest is in artificial Intelligence mainly Agent technology and multi Agent System and machine learning. He had many publications in these fields.

Dr Yasser Omar is currently Associate Professor at Computer Science College of Computing \& Information Technology in AASTMT, Department of Computer Science and Engineering. His interest is in artificial Intelligence mainly Agent technology and multi Agent System and machine learning. He had many publications in these fields.

Adel S. El-Fishawy is currently tenured Associate Professor at Menoufia University Faculty of Electronics Engineering, Department of Electronics and Communication Engineering, His interest is image processing and remote sensing. He had many publications in these fields.

Fathi E. Abd El-Samie is currently Professor at Menoufia University Faculty of Electronics Engineering, in the Department of Electronic and Communication. His current research areas of interest include image enhancement, image restoration, image interpolation, super-resolution reconstruction of images, data hiding, multimedia communications, medical image processing, optical signal processing, and digital communications. Dr. Fathi E. Abd El-Samie was a recipient of the Most Cited Paper Award from the Digital Signal Processing journal in 2008.
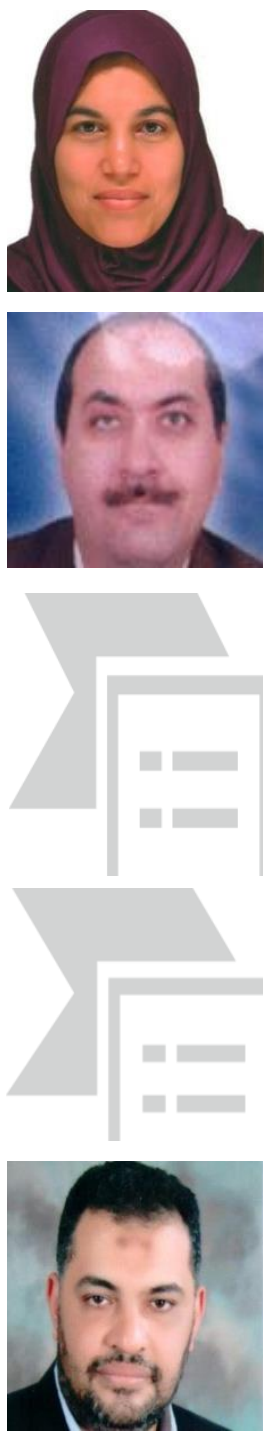